\title{
Influence of acute and chronic disturbance on macrophyte landscape zonation
}

\author{
Alexander Tewfik ${ }^{1,3, *}$, Frederic Guichard ${ }^{1}$, Kevin S. McCann ${ }^{2}$ \\ ${ }^{1}$ Department of Biology, McGill University, Montreal, Quebec H3A 1B1, Canada \\ ${ }^{2}$ Department of Integrative Biology, University Guelph, Guelph, Ontario N1G 2W1, Canada \\ ${ }^{3}$ Present address: WorldFish Center, PO Box 500 GPO, 10670 Penang, Malaysia
}

\begin{abstract}
Although the roles of physical disturbance and successional recovery from such disturbances in structuring natural communities are well known, recent studies have begun to uncover the potential for alternate outcomes or climax states in a number of systems. Here, we examine the distribution of tropical macrophytes at a site with heavy wave exposure and explore equilibrium (microhabitat) and non-equilibrium (patch-dynamic) hypotheses to explain the observed pattern. The existence of a large and distinct zone of prolific macroalgae, undescribed $30 \mathrm{yr}$ earlier, situated between 2 zones with a relatively high abundance of seagrass, challenges the classic successional regime within Caribbean macrophyte beds. Significantly smaller mean size and lower frequency of acute disturbances within the macroalgal-dominated zone, as compared to the outer, mixed macrophyte zone, appears to contradict the highly disturbed environment of classic colonizers. The dominance of macroalgae in the mid-shore zone may be enhanced by the presence of large sediment sizes that are accumulated through the effect of chronic wave stress. Potential causes of overall changes in the hydrodynamic forces at the study site include rise in sea level, increased wave exposure and associated erosion of reefs protecting the coast. We propose a model of macrophyte bed development and distribution that includes the important chronic 'stress' category of wave energy and potential dominance by macroalgae. Increased average wave energy can impose an elevated level of stress leading to modified patterns of macrophyte distributions and changes in the deterministic endpoint of the successional sequence.
\end{abstract}

KEY WORDS: Succession · Colonization · Competition · Waves · Stress · Gaps · Seagrass · Macroalgae

\section{INTRODUCTION}

Disturbance has long been recognized as among the most important factors contributing to community dynamics and variation in species composition (Clements 1916). The response of communities to disturbances has been studied through response rules (sensu Keddy 1989,1992) extending equilibrium-based assembly rules, or through non-equilibrium frameworks based on deterministic successional sequences and integrating dispersal limitation (e.g. patch dynamics, Levin \& Paine 1974) and nonlinear species interactions
(Guichard 2005). Disturbance may kill, damage or displace individuals of a resident species, thereby providing opportunities for new species to colonize the area that would normally be inhibited by the presence or activities of resident species, ultimately 'resetting' the successional clock (Sousa 1984). Most theoretical models assume that ecological succession is initiated by a catastrophic (i.e. acute) disturbance that kills every individual and starts from bare habitat (Connell et al. 1997). However, many disturbance regimes (e.g. waves) may be experienced over a broad range of intensity and duration and may therefore be suitably 
partitioned into acute-short-term, high energy (e.g. annual storms) and chronic-long-term, low energy (e.g. daily tidal movements) forms. Such acute and chronic disturbances on soft substrata may be evidenced by discrete bare depressions (i.e. gaps, blowouts) and areas of altered sediment type, respectively. A distinction between acute and chronic disturbances is critical to understanding coexistence (Grime 1977, Chesson \& Huntly 1997) and recovery patterns (i.e. succession), especially when disturbance events alter the physical environment (e.g. sediments, buffering structures) where they occur (Connell et al. 1997, Hewitt et al. 2003). Recognizing the importance of disturbance in structuring natural communities also leads to a wide ranging discussion about 'alternate' or 'multiple' states, that may emerge as a consequence of particular or suites of disturbance, and the criteria that may define such alternate regimes (Sutherland 1974, Connell \& Sousa 1983, Scheffer \& Carpenter 2003, Knowlton 2004).

Physical disturbance by waves is an important force in the formation of landscape patterns and species distributions within coastal marine systems (Dayton 1971, Short \& Wyllie-Echeverria 1996). Where such disturbances are frequent and/or intense, top-down (Rose et al. 1999, Peterson et al. 2002) and bottom-up forces (Williams 1987, Nielsen 2003) may become less important in structuring the community. Within Caribbean macrophyte beds, abiotic and biotic disturbance regimes, along with a classic successional sequence, have previously been described where pioneering macroalgae are generally excluded over time by competitively superior seagrasses, initially by Halodule wrightii and/or Syringodium filiforme followed by Thalassia testudinum (generally considered the climax species), as nutrients and light become limiting (den Hartog 1971, Patriquin 1975, Williams 1987, Davis \& Fourqurean 2001). This follows the well known colonization/competition trade-offs described in plant ecology where fast growing, short-lived functional groups with greater investments in propagule production are out-competed by the slower growing, longer-lived functional groups. The latter have greater investments in physical structure as environments become less disturbed (Grime 1977, Steneck \& Dethier 1994).

Despite the well-founded paradigms concerning the influence of physical disturbance and the successional sequence of recovery from such disturbances, alternate outcomes or climax state shifts are possible (Williams 1990). Such alternate climax states amongst seagrasses have been considered, and are well documented with the competitively 'inferior' Halodule wrightii often replacing Thalassia (Robbins \& Bell 2000) and Syringodium-dominated communities, which persist in some areas (Peterson et al. 2002).
However, few studies have investigated seagrassmacroalgae interactions or contemplated macroalgae, which occur much earlier in the 'classic' successional sequence, as a possible alternate climax state under natural conditions.

Also, despite the clear importance of acute hydrodynamic forces and associated gap formation driving patch dynamics within seagrass habitats (Patriquin 1975, Bell et al. 1999, Robbins \& Bell 2000), such physical energies may equally result in chronic wave stress and changed sediment characteristics, that may alter growth and interactions between resident organisms, as observed within other coastal systems (Sousa 2000, Siddon \& Witman 2003, Defeo \& McLachlan 2005). Therefore, in order to examine communities for potential alternate climax states, we need to consider various disturbances (e.g. hydrodynamics) as potentially having acute and chronic (i.e. stress) forms generating very different responses, including variation in dominance, in all functional groups subjected to the disturbance (Grime 1977, Steneck \& Dethier 1994, Connell 1997).

Here, we report a historical shift in dominance from seagrass to macroalgal species cover in a shallowwatter macrophyte bed with heavy wave exposure off Barbados (Patriquin 1975). We further explore equilibrium (microhabitat) and non-equilibrium (patchdynamic) hypotheses to explain the maintenance of the various vegetation zones by hydrodynamic forces. More precisely, the microhabitat hypothesis postulates a process by which alternate climax communities may exist at equilibrium in relation to the intensity of 'chronic' (stress) disturbance (i.e. continuous, low-level water movement), dictated by relative water depth and distance from shore. This chronic disturbance alters sediment characteristics that facilitate the re-colonization of areas impacted by acute disturbances by the surrounding, locally dominant macrophyte species, regardless of their status in the 'classic' successional sequence. The patch-dynamic hypothesis (Paine \& Levin 1981, Pickett \& White 1985) suggests that inferior competitors are dynamically maintained through a high frequency of 'acute' disturbances (large, discrete, short-term). Such events may be caused by severe natural (e.g. storms) or anthropogenic (e.g. ship groundings) events, creating bare patches, initially allowing invasion by pioneering macroalgae, but which would be replaced subsequently by more competitive seagrass species (Williams 1990, Short \& Wyllie-Echeverria 1996, Whitfield et al. 2002, Fonseca et al. 2004).

These hypotheses are examined in view of landscape distributions of major macrophyte species, frequency, location and size of acute disturbances (i.e. blow-outs), chrono-sequences of succession within acute (i.e. blowouts) disturbances and sediment distri- 
bution patterns and relationships with macrophyte cover and biomass over the landscape. From these observations we provide a conceptual model and predict that chronic stresses should explain large-scale shifts in dominance while patch dynamics associated with acute disturbances permit coexistence in areas with mixed cover of macroalgae and seagrasses. Specifically, the 'classic' climax state (i.e. Thalassia-dominated areas) should be associated with low levels of acute (low frequencies of small blowouts) and chronic (presence of fine sediments) disturbance, while dense areas of the fleshy macroalgae (i.e. 'alternate' climax state, the rhizomatous Bryopsidales Avrainvillea spp.) should be associated with low levels of acute disturbance but high chronic (presence of coarse sediments) stress with both climax forms reflecting the microhabitat hypothesis. Finally, the configuration of the mixed macrophyte areas will be driven by factors embodied in the patch-dynamic hypothesis, and have high frequencies of large blowouts and mixed sediments, reflecting the presence of both high acute and chronic forces. These observations may be important when considering the large losses of seagrasses and their associated biota, rise in sea level, the extensive level of coastal development, the potential importance of other chronic disturbances such as nutrient loading, and the large scale efforts dedicated to rehabilitating seagrass habitats globally (Short \& Wyllie-Echeverria 1996, McClelland \& Valiela 1998).

\section{MATERIALS AND METHODS}

Study site. Observations were made off Bath, located on the east coast of Barbados, southeastern Caribbean Sea, during April and May of 2003. The macrophyte beds examined lie within the lee of a $100 \mathrm{~m}$ wide algal and coral encrusted rocky platform approximately 200 to $300 \mathrm{~m}$ from shore (Patriquin 1975, Lewis \& Oxenford 1996). This barrier provides some protection from the full force of Atlantic Ocean swells arriving from the northeast. The few reef lagoons and semi-protected bays around the coast of Barbados combined with strong wave energies limit the overall extent of macrophytes, especially seagrasses (Patriquin 1975).

The inshore area off Bath is dominated by seagrasses Thalassia testudinum and Syringodium filiforme as well as fleshy (Avrainvillea spp., Caulerpa spp., Udeota spp.) and calcareous (Halimeda spp., Amphiroa spp.) green algae (Lewis \& Oxenford 1996). Bathymetry and distribution of sediments, ranging from sand to rubble, have been described as 'complex' (Patriquin 1975). Waters over the macrophyte beds are shallow $(<2 \mathrm{~m}$, mean tidal range approx. $0.7 \mathrm{~m}$ ) but generally turbulent, except during a few hours around low tide
(Patriquin 1975). Average wave heights are 0.3 to $0.6 \mathrm{~m}$ during high tide, breaking over the entire embayment, and can exceed $1 \mathrm{~m}$ during winter months when the coast endures large and frequent swells. Blowouts, crescent shaped macrophyte free depressions or gaps characteristic of acute physical disturbance, occur in all substratum types at Bath (Patriquin 1975). These are on average $3.6 \mathrm{~m}^{2}$ in area and $40 \mathrm{~cm}$ deep. However, blowouts are predominant in areas of low macrophyte abundance associated with early stages of succession, including the outermost regions of the bed where wave action is very intense (Patriquin 1975).

Macrophyte biomass and percent cover. Two poles planted inline on the beach were used to maintain a straight course across the bed. The transect tape was secured to the substratum at various points to prevent its movement. Two snorkellers assessed $( \pm 2 \mathrm{~m}$ from transect line) macrophyte cover while swimming in to shore, noting where changes in species dominance (transition zones) in the community occurred. A factorial sampling design was used to place quadrats for a detailed assessment of the macrophyte community. Three $0.25 \times 0.25 \mathrm{~m}$ quadrats were placed by snorkellers in each zone, one in the middle and 2 at $1 \mathrm{~m}$ distance inwards from both transition edges. To collect macrophyte biomass data, a total of eighteen $100 \mathrm{~m}$ transects were run out perpendicularly to shore every $5 \mathrm{~m}$, starting from the nearshore edge of the macrophyte bed. In nine of these, we also collected percent cover data every $10 \mathrm{~m}$. The macrophyte free swash zone (between the low tide mark and inner seagrass edge), was surveyed subsequently for macrophyte cover and width to correct absolute distances from shore at mean low tide.

The percent cover of all macrophytes within each $0.25 \times 0.25 \mathrm{~m}$ quadrat was assessed prior to biomass removal. All aboveground macrophyte structures within a quadrat were then removed and placed into bags. Seagrasses, macroalgae and associated detritus were separated, rinsed of sediment and dried for approximately $24 \mathrm{~h}$ at $80^{\circ} \mathrm{C}$ to constant mass, then weighed on an electronic balance to the nearest $0.01 \mathrm{~g}$. Biomass was later expressed as $g$ dry mass $\mathrm{m}^{-2}$ (g DM $\mathrm{m}^{-2}$ ) and converted to percent of total biomass. A PVC pole with $0.05 \mathrm{~m}$ graduations was used to measure the water depth at each quadrat site. All water depths were corrected to mean low tide using tide tables established for Bridgetown, Barbados.

Sediment and associated macrophyte survey. Four transects $(10,30,50$ and $70 \mathrm{~m}$ along the shore) were used to investigate the relationships between macrophyte biomass, cover and sediment composition. Quadrats were placed at 23, 59 and $99 \mathrm{~m}$ (corrected for swash zone) along transects in order to coincide with the approximate centres of the previously established 


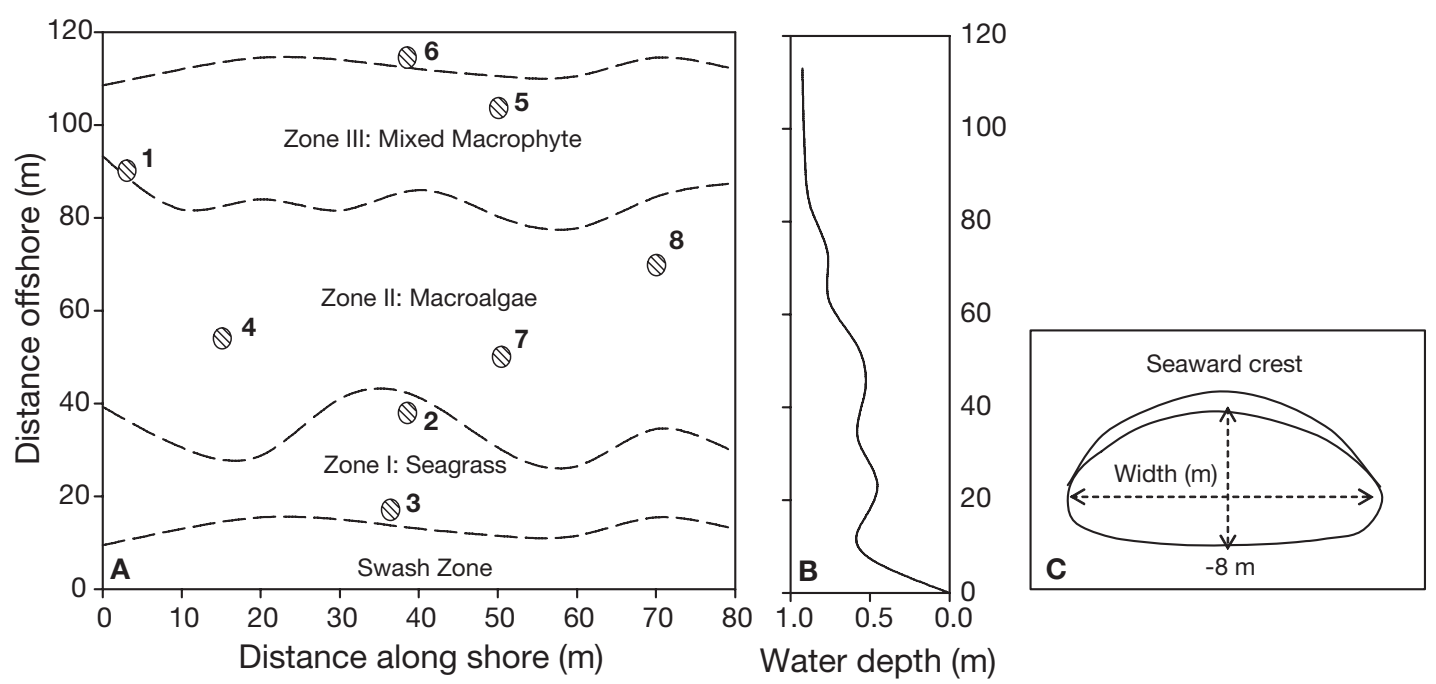

Fig. 1. Detail of study area from visual surveys off Bath, Barbados. (A) Layout of vegetation zones and positions of blowouts (Q) (see Fig. 5 for details). Swash zone primarily bare sand substratum with no macrophytes; Zone I: mixed seagrass (Syringodium, Thalassia), Zone II: primarily the macroalga Avrainvillea, Zone III: mixed seagrass (Thallassia syringodium) and macroalga (Avrainvillea). Dashed lines indicate approximate zone boundaries with exception of outermost line indicating furthest extent of surveys. (B) Mean water depth profile. All values corrected to mean low tide. (C) Schematic of blowout indicating crest, width measure to estimate area and placement of profile transect (crest to $-8 \mathrm{~m}$ )

zones. Percent cover and biomass of all macrophytes were collected, followed by the removal of all sediment using a hand shovel down to approximately $0.1 \mathrm{~m}$ in depth. Macrophyte biomass was treated as before, but with rinsed sediments added to appropriate sediment samples. Sediments were dried for approximately $24 \mathrm{~h}$ at $80^{\circ} \mathrm{C}$ and separated into 3 categories using a series (Wentworth scale) of sieves (cobble, $>6.73 \mathrm{~mm}$, Phi $<$ -2 ; gravel, $1.52-6.73 \mathrm{~mm}$, Phi -2 to -1 ; sand and silt, $<$ $1.52 \mathrm{~mm}$, Phi $>-1$ ). These groups were then weighed (to nearest $0.01 \mathrm{~g}$ ) and converted into percentages.

Blowout size, distribution and profiles. We established the positions within the landscape of all blowouts encountered during transect surveys, and measured their maximum widths (Fig. 1c) to the nearest $0.1 \mathrm{~m}$ using a transect tape. Subsequent calculations closely approximated individual gap area (based on a generic half circle area model: width $\times 0.5 \pi \mathrm{r}^{2}$ ) and total area of blowouts within a zone.

A small subset of blowouts were randomly chosen and assessed in more detail. Transects were laid across the middle (perpendicular axis to shore, Fig. 1c) of blowouts within each of the 3 vegetative zones, beginning at the seaward crest and moving back towards shore. Quadrats $(0.25 \times 0.25 \mathrm{~m})$ were positioned at 0,1 , 2 , 4, and $8 \mathrm{~m}$ and all aboveground macrophytes were removed. The zero position (i.e. crest) represents the 'undisturbed front' of the blowout (i.e. gap) while quadrat samples moving back $(-1$ to $-8 \mathrm{~m})$ represent areas with greater recovery time since disturbance. Material from the quadrats was treated as previously described for biomass surveys.
Statistical analyses. All statistical analyses were performed using SYSTAT version 10.2 (SYSTAT software 2002). Arcsine square root transformations were performed on percent macrophyte biomass and cover values, and on percent sediment to convert distributions from binomial to nearly normal (Zar 1999). Analysis of variance was performed on transformed percent data using the general linear model (GLM) component of SYSTAT, where interaction models are designated and categorical variables are set manually. Normality and homogeneity of variances were confirmed within SYSTAT. All post hoc multiple comparisons were performed using Tukey's test, which is considered to be robust with respect to departures from underlying assumptions of multiple comparisons (Keselman 1976). Finally, linear regression analyses were performed between raw (no transformation) percent sediments (independent) and macrophyte percent cover (dependent) data.

\section{RESULTS}

The study encompassed a total area of approximately 0.8 ha. Distances from shore were all corrected to mean low tide, with subsequent measures of the swash zone width. Three relatively distinct vegetative zones (Zone I: seagrass, Zone II: macroalgae, Zone III: mixed macroalgae/seagrass) were established based on large-scale visual surveys along 18 transects (Fig. 1). Distributions of macrophyte percent cover (Fig. 2A) and biomass (Fig. 2B), collected from 81 and 


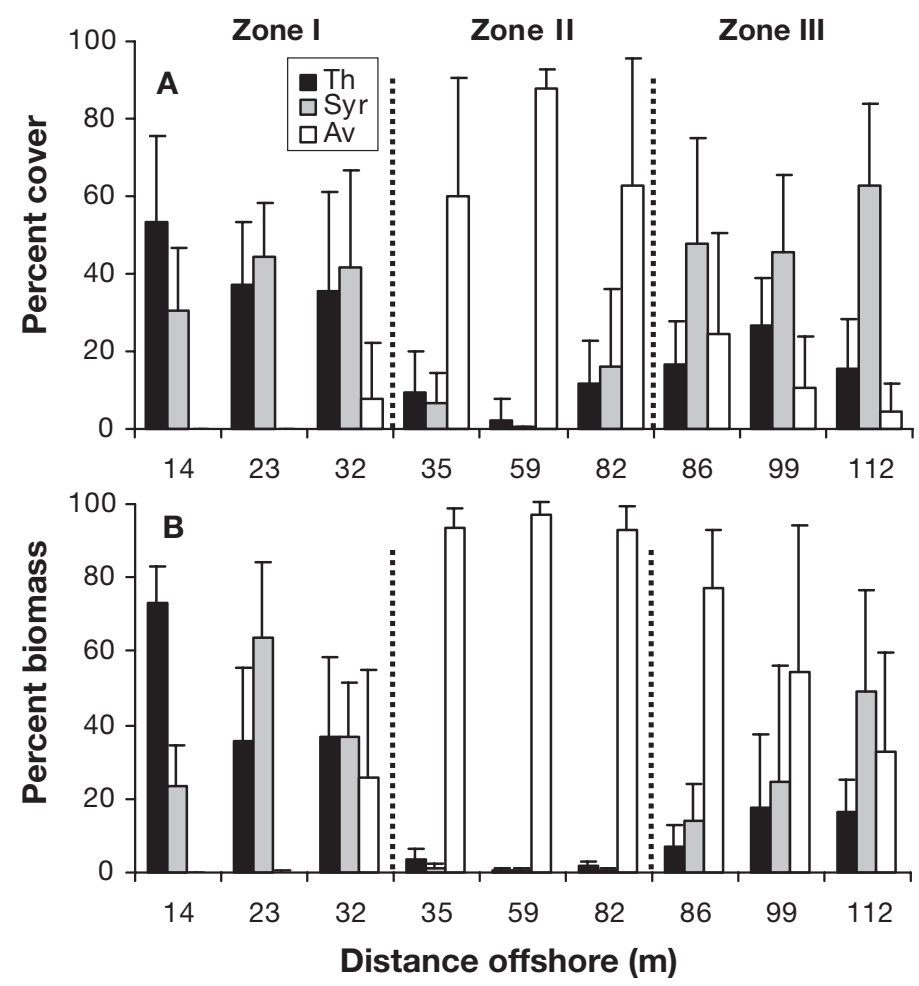

Fig. 2. Distribution of principle macrophyte species within vegetation zones. (A) Percent cover + SD $(n=9)$. (B) Percent biomass + SD $(\mathrm{n}=18) . T h=$ Thalassia, $\mathrm{Syr}=$ Syringodium, $\mathrm{Av}=$ Avrainvillea spp. Distances corrected to swash zone. Dashed lines separate zones

162 quadrats, respectively, correspond well to vegetation zones and transitions. These patterns also represented control data (i.e. undisturbed) to that of the gaps (i.e. blowouts). The seagrasses Thalassia and Syringodium and the species complex of the rhizomatous chlorophyte Avrainvillea (Bryopsidales) (predominantly A. digitata) (Littler et al. 2004) constituted the vast majority of biomass and cover. Other species of macroalgae and detritus represented $<2.4 \%$ and $<1 \%$ of biomass, respectively, and were not included in subsequent analyses.

Two-way analysis of variance for transformed percent cover, pooled into zones, indicated a significant interaction between macrophyte species and zone $\left(F_{4,72}=54.3, \mathrm{p}<0.0001\right)$. Pairwise comparisons confirmed significantly $(\mathrm{p}<0.001)$ lower and higher levels of Avrainvillea than either seagrass species in Zone I $(2.6 \%)$ and II (70.2\%) (Fig. 2A), respectively. No significant differences were found between the 2 seagrass species in Zones I or II. However, results from Zone III indicated Syringodium (52.1\%) cover was significantly higher than either Thalassia (19.6\%) or Avrainvillea (13.1\%) (Fig. 2A).

Similar analyses for transformed percent biomass data pooled into zones, also showed a significant inter- action between macrophyte species and zone $\left(F_{4,153}=\right.$ 94.6, p < 0.0001) Subsequent pairwise comparisons indicated significantly ( $p<0.001$ ) lower and higher levels of Avrainvillea than either seagrass species in Zone I (8.6\%) and II (94.5\%), respectively (Fig. 2B). No significant differences were found between seagrasses in Zone I or II, or amongst any macrophytes in Zone III (Fig. 2B).

Distribution of sediment classes indicated dominance of sand in Zone I (98.4\%) and Zone III (67.5\%) and high proportions of cobble in Zone II $(42.1 \%)$ (Fig. 3). Two way analysis of variance for percent sediment data showed a significant interaction between sediment type and zone $\left(F_{4,3}=18.86, \mathrm{p}<0.0001\right)$. Subsequent pairwise comparisons indicated significantly ( $p<0.001$ ) higher levels of sand than either cobble or gravel in Zones I and III (Fig. 3). No significant $(<0.05)$ differences were detected between cobble $(42.1 \%)$ and sand (47.4\%) in Zone II, with only gravel (10.4\%) being significantly lower than sand (Fig. 4).

In our analysis of relationships between macrophytes and underlying sediments we concentrated on the groups that had previously shown strong differences in analyses of variance. Thus, Thalassia and Syringodium were grouped simply as total seagrass and the gravel sediment category was omitted, given its minor contribution to overall quantity of sediment. Moderate (regression coefficient) and significant positive and negative regressions occurred between cobble and Arainvilliea $\left(\mathrm{R}^{2}=0.44, \mathrm{p}=0.018\right)$ and cobble and seagrass $\left(\mathrm{R}^{2}=0.54, \mathrm{p}=0.007\right)$ percent cover, respectively. Reverse trends occurred for comparisons of Arainvilliea with sand $\left(\mathrm{R}^{2}=0.45, \mathrm{p}=0.016\right)$ and seagrasses with sand $\left(\mathrm{R}^{2}=0.54, \mathrm{p}=0.006\right)$.

The survey of blowouts ( $\mathrm{N}=50)$ indicated fairly even distribution of these acute disturbance features across the 3 zones (Fig. 4). However, the mean individual size $\left(F_{2,49}=9.06, \mathrm{p}<0.0005\right)$ and associated total percent

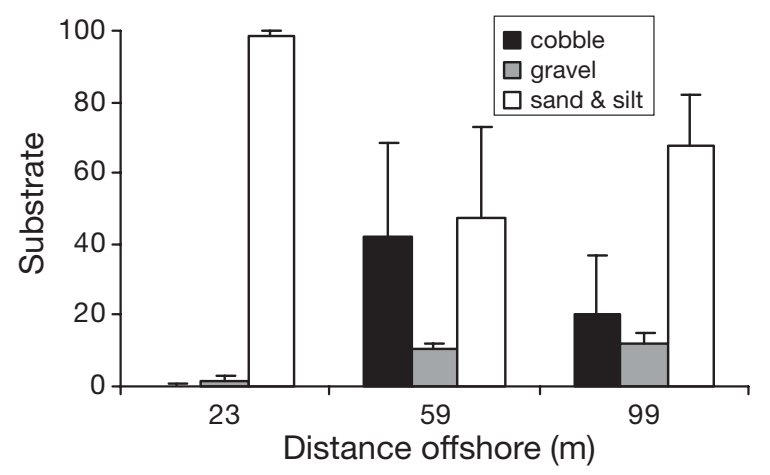

Fig 3. Percent sediment type $+\mathrm{SD}(\mathrm{n}=4)$ within zones. Three offshore distances represent sampling at approximate centre of each main zone (I: seagrass, II: macroalgae, III: mixed) (see Fig. 2) 


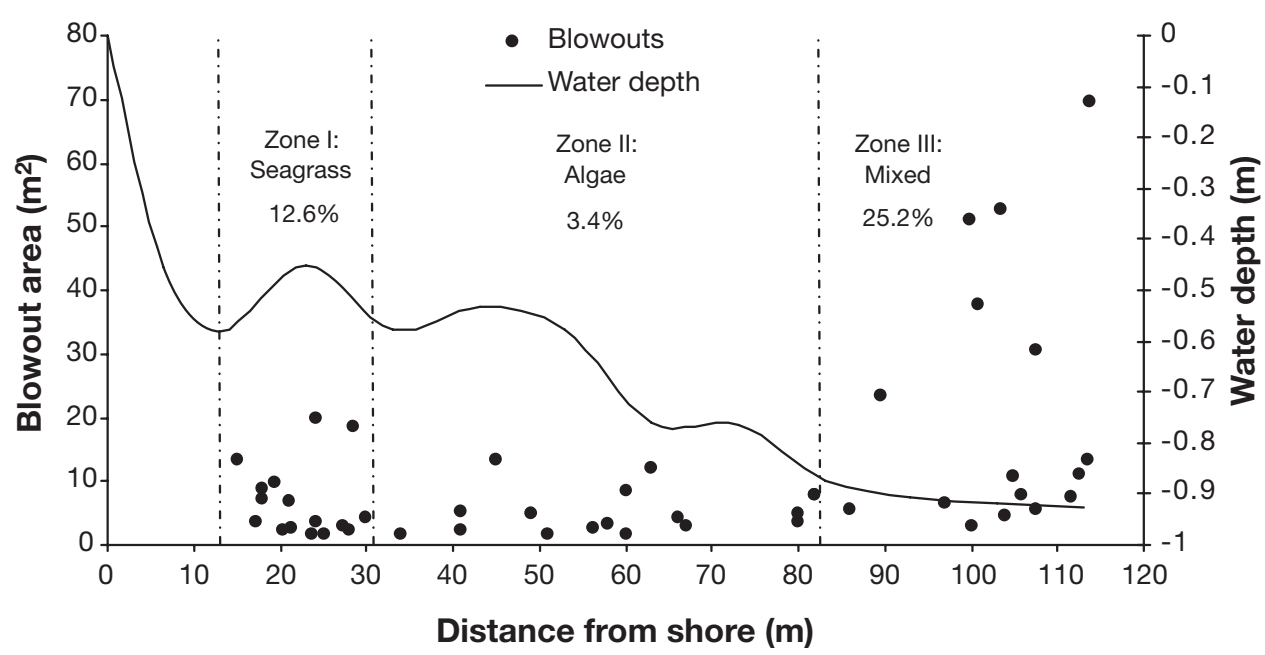

Fig. 4. Individual blowout area (Zone I, $\mathrm{n}=16$; Zone II, $\mathrm{n}=17$; Zone III, $\mathrm{n}=17$ ), distribution and associated water depth at mean low tide. Blowout area is estimated as width $\times 0.5 \pi \mathrm{r}^{2}$. Dotted lines indicate approximate zone boundaries (see Fig. 1). First area (shoreward from Zone I) is swash zone with no blowouts. Percentages are total zone areas covered by blowouts. Mean size of blowouts within zones is significantly different $\left(F_{2,49}=9.06, \mathrm{p}<0.0005\right.$, pairwise significant differences: Zone I vs. III;

Zone II vs. III)
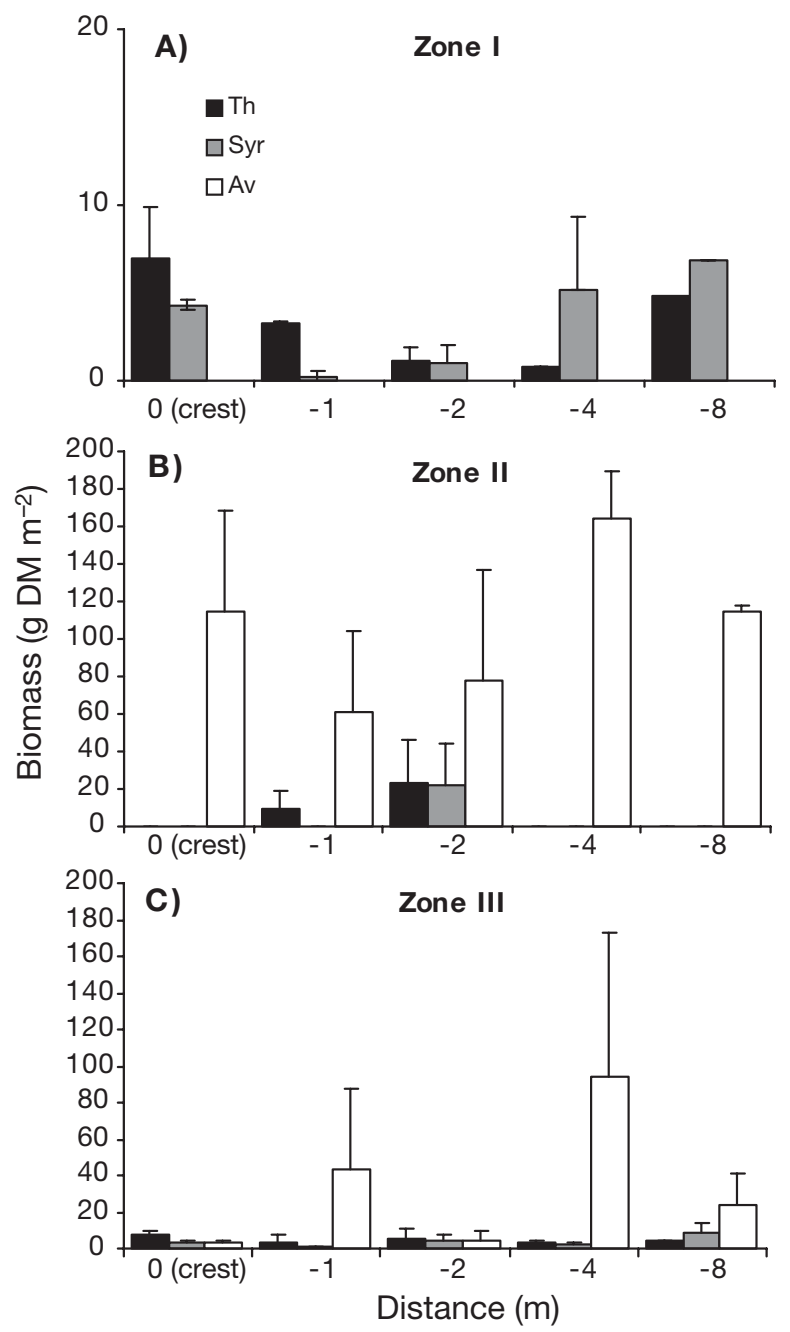

coverage of blowouts was very different between zones, with Zone III having much larger blowouts then either Zones I or II. In general, macrophyte biomass from blowouts indicated that final recolonization of these acute disturbance areas (i.e. areas experiencing the longest recovery times at the back of the gap) largely reflected the vegetation composition of the surrounding zone (also seen as the 'crest' data). This does not necessarily conform to the 'classic' successional sequence for these tropical macrophyte beds (Fig. 5). This was most clear in Zone I (seagrass) where Avrainvillea did not appear (Fig. 5A) and where seagrasses were most abundant. Within Zone II (macroalgae) blowouts the oldest areas of disturbance further back from the crest were populated with significant (note difference in scales) amounts of Avrainvillea biomass with seagrasses appearing in the middle of the blowouts (Fig. 5B). The outermost Zone III (mixed) showed high variability in the later stages of recolonization within blowouts (Fig. 5C), reflecting the mixed species composition of Zone III at the landscape level (Fig. 2). In all cases the final stages of recolonization, oldest areas at the back of the blowouts, reflected

Fig. 5. Biomass of macrophytes, seagrasses $($ Th $=$ Thalassia, Syr = Syringodium), and Avrainvillea spp. (Av) measured along transects within blowouts in each of the 3 zones: (A) Zone I $(\mathrm{n}=2)$; (B) Zone II $(\mathrm{n}=3)$; (C) Zone III $(\mathrm{n}=3)$. The zero $m$ position (i.e. crest) represents the undisturbed seaward front of the blowout (i.e. gap) while quadrat samples moving away from zero $m$ represent areas of greater recovery time since disturbance (e.g. $-8 \mathrm{~m}$ has the greatest recovery time) (see Fig. 1C). Data are means + SD. See Fig. 1 for details on blowout locations within zones 
the surrounding zone and seemingly appeared as miniature models of community organisation at the larger zone scale.

\section{DISCUSSION}

It is well known that the configuration of communities and the interactions within them are intimately connected to the disturbances they undergo and the functional groups of organisms that are capable of withstanding such disturbances (Dayton 1971, Sousa 2000). The macrophyte community at Bath had been previously studied and described as mixed seagrass cover (see Fig. 2, Patriquin 1975) maintained by physical disturbances in the form of blow-outs (Patriquin 1975). Although blowouts are still a major feature of the landscape in the present study, we observed the presence of a distinct and dense zone of fleshy macroalgae, consisting largely of a single genus (Avrainvillea) in the mid-shore. This historical shift in dominance from seagrass to macroalgae, which was maintained through 2005 and 2006 (F. Guichard unpubl. data), raises the issue of mechanisms that may be responsible for the origins and maintenance of such a pattern, given the wellknown classic successional sequence. The new pattern is made more intriguing by the existence of significant areas of competitively 'superior' seagrasses (Thalassia and Syringodium) in the near and offshore zones proximate to the bed of macroalgae, providing suitable sources of propagules or vegetative growth to eventually fill gaps in general, and specifically the area of the mid-shore. Furthermore, high wave exposure and the reported importance of generalized wave disturbance on our study site suggest these as the primary factors controlling community structure. We find no evidence to suggest that historical changes in nutrient availability (i.e. agricultural practices or urbanization of the shore) or vessel traffic (i.e. groundings, prop scarrings) can explain observed changes in community structure independently of wave action, although dissolved nutrients and ship traffic certainly have influence elsewhere (Fonseca et al. 2004, Armitage et al. 2005). Our results precisely confirmed the existence of 3 fairly distinct vegetation zones (Thalassia dominated, Avrainvillea spp. dominated, mixed macrophytes) associated with distinct distributions of sediment (a proxy for chronic stress levels), as well as size and frequencies of acute disturbances (i.e. blowouts). We propose several mechanisms to account for the maintenance of these zones. These mechanisms allow for the existence of an alternate state (in the form of a macroalgal dominated zone).

A significant debate rages in the literature on the existence of alternate stable states in nature and on the correct criteria to define them (Sutherland 1974, Connell \& Sousa 1983, Sutherland 1990, Scheffer \& Carpenter 2003, Knowlton 2004). However, the present study simply provides evidence for the existence of an 'alternate' state (whose stability is not tested) which exists under different physical conditions (i.e hydrodynamics, bathymetry, sediments) from those that are the norm for the formation of the 'classic' climax community. This may, as a consequence, challenge the generalisation of colonisation-competition tradeoffs within such systems, and requires a new testable conceptual model for the development and distribution of macrophyte beds incorporating both acute disturbance and chronic stress and having compatability with our findings.

\section{Maintenance of dominance and diversity across scales}

The microhabitat hypothesis

The specific biotic (propagule density, vegetative structures) and abiotic (hydrodynamics, bathymetry, sediments) characteristics of local habitats are known to influence patterns of dominance among seagrass species (Robbins \& Bell 2000). However, macroalgae have often been described as poor competitors in seagrass ecosystems, although few seagrass-macroalgal interactions studies have been reported (den Hartog 1971, Williams 1990, Hughes et al. 2004). Our results reveal physical properties of macrophyte habitats, such as gradients of wave exposure, water depth and sediment type that coincide with patterns of dominance involving macroalgae-seagrass interactions. Mechanisms embodied in the microhabitat hypothesis are thus thought to maintain patterns of dominance in the near-shore seagrass Zone I (Thalassia testudinum and Syringodium filiforme) and the mid-shore macroalgal Zone II (Avrainvillea spp.). Here, the locally abundant seagrass macrophytes ultimately re-colonize and dominate sites of acute disturbance (i.e. blowouts). It should again be noted that Avrainvillea spp. dominated macroalgal Zone II, in contrast to observations made more than $30 \mathrm{yr}$ previously where this same area was covered exclusively by seagrasses, with 'dense' macroalgae occurring only further offshore (Patriquin 1975).

Sediment grain size distribution within zones was relatively specific, with sand predominating (>98\%) in Zone I and cobble being a major component (42\%) of Zone II. Chronic wave stress would seem a plausible mechanism assisting in the maintenance of sediment grain size composition, given the bathymetric and hydrodynamic features of this coastal landscape. We 
may consider the generic 'dissipative' beach profile, or the more tide-range specific 'barred dissipative' beach profile described by coastal engineers, as appropriate descriptions of this coast (Carter 1988, Masselink \& Short 1993). Such areas are characterised by spilling breakers over a flat beach, which allow the formation of nearshore bars and troughs parallel to the shoreline. Such bathymetry may assist in the accumulation of certain sediment sizes. Significant changes in sediment grain size affect porosity, stability and biogeochemical fluxes, making it difficult for succession to progress to the original state (Connell et al. 1997, Hewitt et al. 2003). The general pattern of macrophyte groups' (rhizomatous algae vs. seagrasses) preferences for certain ranges of sediment grain size is suggested in our regression analyses. Specifically, the ability of macroalgae possessing strong anchoring rhizoidal holdfasts, such as that of Avrainvillea, to colonize larger, unconsolidated sediments and areas of high wave energy is well known (Davis \& Fourqurean 2001, Littler et al. 2004). The lower frequency and total cover of blowouts in macroalgal Zone II, as compared to mixed Zone III, suggests that Avrainvillea is maintained as an alternate climax community, rather than through acute disturbances and associated patch dynamics described below. The re-colonization pattern observed within blow-outs specific to Zone I and Zone II indicate a predominance for final re-colonization by the surrounding, locally dominant macrophyte species, which is specifically reflected in the undisturbed front or 'crest' of the blowouts. The existence of seagrasses within Zone II, and specifically Zone II blowouts, does not suggest any recruitment or dispersal limitation for seagrass which would simply eliminate competition with the macroalga Avrainvillea.

\section{The patch-dynamic hypothesis}

Acute disturbances and resulting patch dynamics have long been shown to represent a major mechanism promoting coexistence (Paine \& Levin 1981, Pickett \& White 1985). In seagrass communities, and more specifically in the macrophyte community present at Bath, acute wave disturbances have been suggested as a mechanism explaining the maintenance of diversity in a community dominated by Thalassia (Patriquin 1975, Bell et al. 1999). However, within the macroalgal-dominated Zone II described in the present study, a distinctly lower overall area (3.4\%) of acute disturbance exists. The mean size of acute disturbances is also significantly smaller than that in the mixed Zone III, but not so in the seagrass-dominated Zone I. These results suggest a relatively decreased influence of acute disturbances in driving the domi- nance of macroalgae, and run counter to general models of ecological succession where pioneering species, such as the macroalga Avrainvillea, should dominate the most heavily disturbed areas.

In contrast, the mechanisms of the patch-dynamic hypothesis are thought to explain the formation of the mixed macrophyte assemblage in the offshore Zone III, as suggested by Patriquin (1975). The limitation of chronic wave stress, due to increased water depth, along with mixed sediment grain size composition (cobble $20.3 \%$, gravel $12.2 \%$, sand $67.5 \%$ ) facilitates the existence of a variety of macrophyte functional groups that may exhibit a variety of sediment preferences. The significantly larger mean size, occasionally overlapping, and total area (25.2\%) of blowouts further supports the hypothesis that the mixed community is largely driven by formation of gaps created during acute disturbance events in the offshore zone. Blowout data from the Zone III again suggest the more traditional colonization/competition trade offs and patch dynamics are occurring between and amongst macroalgae and seagrasses, as seen within the classic successional sequence (Patriquin 1975, Davis \& Fourqurean 2001). The significantly higher percent cover of Syringodium in Zone III is further evidence of acute disturbance predominating, given the status of this seagrass as a secondary colonizer.

\section{Partitioning of the hydrodynamic disturbance regime}

The maintenance of spatial patterns and of diversity in seagrass ecosystems has been explained in relation to disturbance intensity (Hemminga \& Duarte 2000). However, our study shows that disturbance plays a generalized role in the maintenance of diversity, but more importantly that actual successional sequences following disturbance may be driven by habitat properties and/or reinforcing mechanisms leading to alternate climax states. More precisely, our results suggest that the overall physical disturbance (i.e. hydrodynamics) regime needs to be viewed as 2 sub-categories: (1) an acute form expressed in blowouts - saucer shaped depressions - where resident organisms are at one time ripped away leaving bare sediment; and (2) a chronic form expressed as a continuous, low-level hydrodynamic force generated by every wave breaking across the landscape. This chronic form results in a high overall average wave energy whose intensity is most pronounced in shallow waters over nearshore bars and progressively closer to shore. The fact that a large distinct zone of prolific macroalgae (i.e. Avrainvillea), with seagrass largely confined to recently disturbed areas, exists between 2 zones with relatively high abundances 

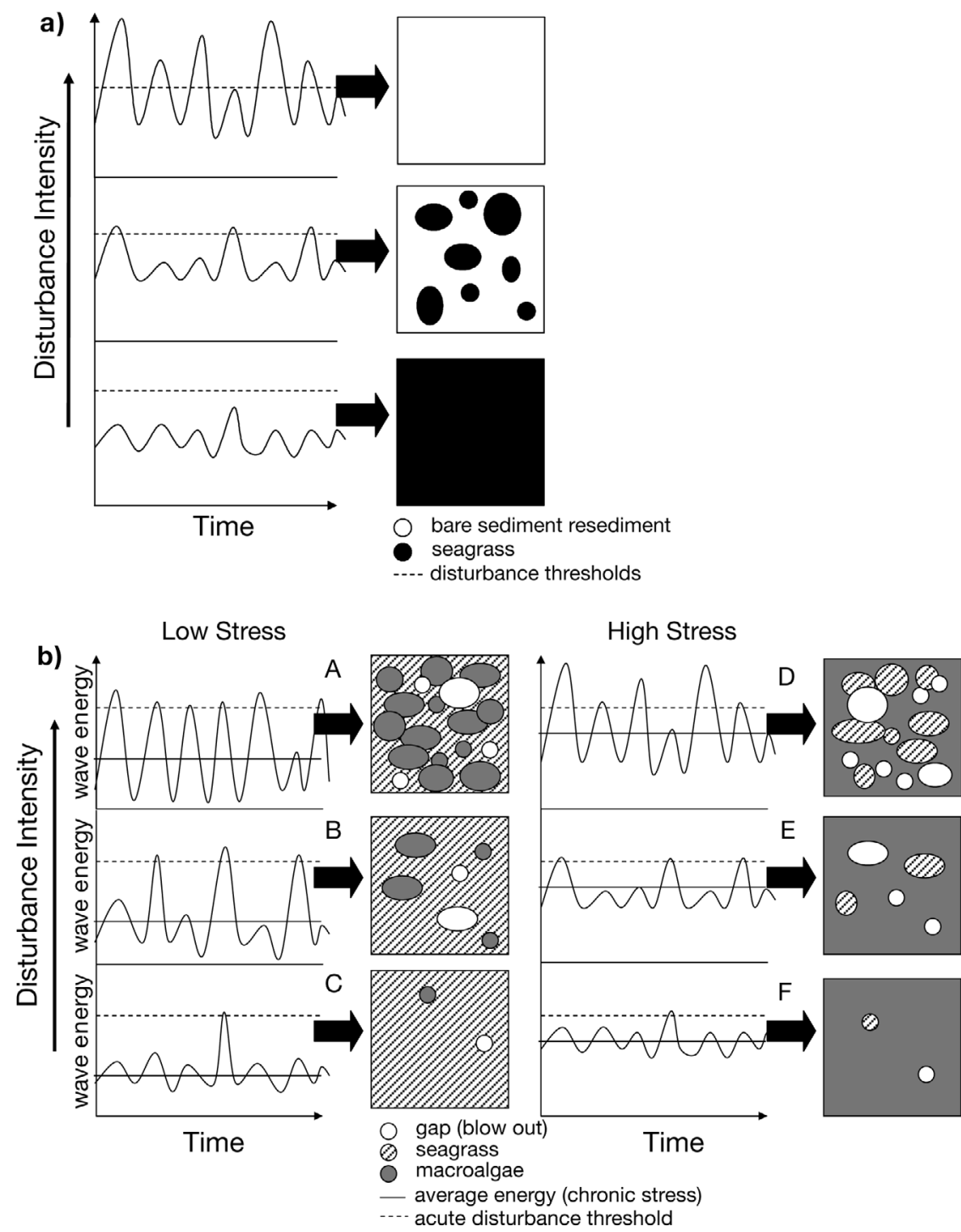

Fig. 6. Models of macrophyte bed development and distribution. (a) Original model redrawn from Hemminga \& Duarte (2000), Fig. 3.9, describing importance of disturbance amplitude and frequency in the development of patchy or continuous meadows and the maintenance of bare sediments. (b) Modified model describing how chronic stress (continuous, high average wave energy, solid line) and acute disturbance (high amplitude-above threshold, dashed line) affect macrophyte dominance and patchiness within nearshore landscapes (see: 'Discussion': Partitioning of the hydrodynamic disturbance regime). Hatched area represents seagrass species (Thalassia and Syringodium), solid grey represents macroalgae (i.e Avrainvillea spp.) and white represents bare areas or blowouts. Under low frequency of acute disturbance and low chronic stress, seagrasses dominate (C). Under higher frequencies of acute disturbance and low chronic stress, seagrass remains dominant, with various levels of blowouts and stages of recolonization along 'classic' successional sequence $(\mathrm{A}, \mathrm{B})$. High chronic stress causes changes in sediment characteristics and switch in dominance to stress tolerant macroalgae (F). Combinations of higher frequencies of acute disturbance and high chronic stress cause increasing frequency of bare areas and stages of recolonization with macroalgae remaining as the successional dominant $(\mathrm{D}, \mathrm{E})$

of seagrass, challenges the classic successional regime and the existence of well established competitioncolonization tradeoffs in these communities.

In order to integrate the observations made in this study into a more generic description of macrophyte bed development and distribution we propose modifications to an earlier model (Hemminga \& Duarte 2000),
(Fig. 6a). We first add the important chronic 'stress' category of physical wave energy impacts on macrophytes (Fig. 6b). This is highlighted with a clear distinction between (1) average wave energy and (2) frequency of high amplitude fluctuations bringing wave energy above the threshold for acute disturbance formation (i.e. blowouts). A focus on extreme wind/ 
wave conditions in studies of seagrass landscape patterns (Fonseca et al. 2002) may ignore more subtle yet more common, average, or chronic stress conditions. Under moderate wave energy, such acutely disturbed areas may be initially colonized by macroalgae, as in Zone III, but revert to seagrass with ample time between disturbances (Fig. 6b:B,C). However, when the period of time between acute disturbances is short, early colonizers such as macroalgae can form the dominant cover (Fig 6b:A). What is important here is that macroalgal dominance is also possible when average wave energy imposes an elevated stress level leading to a reversal of the expected successional sequence as in Zone II (Fig. 6b:D-F). These alternative hypotheses can be tested in the field by experimental manipulations of macrophyte cover, and using time sequences of succession within 'migrating' disturbances (Patriquin 1975, Peterson et al. 2002).

It has been clearly recognized that macroalgae form an important element within macrophyte successional dynamics, regardless of their competitive rank (den Hartog 1971, Patriquin 1975, Williams 1990, Peterson et al. 2002). However, with the realization that macroalgae may in fact form alternate climax states, which may fundamentally change community dynamics and rates of recovery, their inclusion in models of macrophyte distribution and development are required, regardless of the persistence of such alternate states or the exact mechanism which allows this to happen (Knowlton 2004).

\section{CONCLUSION}

By revealing landscape-level shifts in macrophyte dominance, this work suggests that an apparently single overwhelming disturbance regime, such as wave energy, may need to be partitioned into separate elements, i.e. acute and chronic, which may themselves be complicated by interactions with various biotic (propagule density, vegetative structures) and abiotic (bathymetry, sediments) elements. Such partitioning is likely to yield different mechanisms for the observed pattern of community structure over relatively small scales (10s to $100 \mathrm{~s}$ of $\mathrm{m}$ ). The microhabitat hypothesis states that locally preferred conditions (e.g. sediment) and/or locally available colonists may overwhelm any generally conceived pattern of the deterministic endpoint of succession. The patch-dynamic hypothesis follows the more widely accepted 'rules' of dynamic succession with early colonizers being replaced by longer-lived species as a result of resource competition or simple attrition. Our results provide additional information on the importance of chronic, low-level forces in structuring nearshore marine communities (Connell et al. 1997, Hewitt et al. 2003, Siddon \& Witman 2003, Conlan \& Kvitek 2005).

Any generally conceived models of succession need to be strictly examined in light of various scales of disturbance and community structure which may change 'rapidly' as evidenced by the appearance of the dense zone of Avrainvillea spp. in the mid-shore more than 30 years after initial observations (see Fig. 2, Patriquin 1975). Long-term changes in patterns of hydrodynamic forces leading to changes in sediment characteristics within the mid-shore would have allowed macroalgae (i.e. Avrainvillea) to colonize successive winter storm 'acute' gaps rather than recovering to the traditional seagrass climax community. Gradually, over $30 \mathrm{yr}$, the macroaglae could have taken over the mid-shore, resulting in the pattern we see today. Again, nothing suggests that alterations in nutrient availability or increased vessel traffic may have been responsible for the observed changes. Speculation as to the causes of the overall changes in the natural hydrodynamic forces in the area of the study include rise in sea level, increased wave exposure and associated erosion of reefs protecting the coast (Grigg 1998, Lewis 2002). However, the dynamic transition described here will provide more general insights into the functioning of disturbed systems and the sensitivity of colonizationcompetition tradeoffs to environmental fluctuations. The general understanding of such landscape level transitions is of great relevance for the conservation of seagrass ecosystems worldwide given large-scale losses, rise in sea level, coastal development, increasing chronic disturbances (e.g. nutrient loading) and the significant efforts dedicated to rehabilitating seagrass habitats globally.

Acknowledgements. We thank the staff of the Bellairs Marine Laboratory for their help in logistical support. This project was funded through a McGill Major scholarship through the J.W. McConnell Foundation to A.T. and an NSERC grant to K.S.M. We are indebted to the undergraduate students of the McGill Tropical Ecology Field course of 2003, especially Sonja Bodmer-Roy, for their contribution to the data collection efforts. Finally, comments by Susan Bell, Mark Fonseca and an anonymous reviewer were extremely helpful.

\section{LITERATURE CITED}

Armitage AR, Frankovich TA, Heck KL, Fourqurean JW (2005) Experimental nutrient enrichment causes complex changes in seagrass, microalgae, and macroalgae community structure in Florida Bay. Estuaries 28:422-434

Bell SS, Robbins BD, Jensen SL (1999) Gap dynamics in a seagrass landscape. Ecosystems 2:493-504

Carter RWG (1988) Shoreline hydrodynamics. In: Carter RWG (ed) Coastal environments. Academic Press, London, p 99-149

Chesson P, Huntly N (1997) The roles of harsh and fluctuating 
conditions in the dynamics of ecological communities. Am Nat 150:519-553

Clements FE (1916) Plant succession: an analysis of the development of vegetation. Carnegie Inst Wash Publ 242: $1-512$

Conlan KE, Kvitek RG (2005) Recolonization of soft-sediment ice scours on an exposed Arctic coast. Mar Ecol Prog Ser 286:21-42

Connell JH (1997) Disturbance and recovery of coral assemblages. Coral Reefs 16 (Suppl):S101-S113

Connell JH, Sousa WP (1983) On the evidence needed to judge ecological stability or persistence. Am Nat 121:789-824

Connell JH, Hughes TP, Wallace CC (1997) A 30-year study of coral abundance, recruitment, and disturbance at several scales in space and time. Ecol Monogr 67:461-488

Davis BC, Fourqurean JW (2001) Competition between the tropical alga, Halimeda incrassata, and the seagrass, Thalassia testudinum. Aquat Bot 71:217-232

Dayton PK (1971) Competition, disturbance, and community organization: The provision and subsequent utilization of space in a rocky intertidal community. Ecol Monogr 41: 351-391

Defeo O, McLachlan A (2005) Patterns, processes and regulatory mechanisms in sandy beach macrofauna: a multiscale analysis. Mar Ecol Prog Ser 295:1-20

den Hartog C (1971) The dynamic aspect in the ecology of seagrass communities. Thalassia Jugosl 7:101-112

Fonseca M, Whitfield PE, Kelly NM, Bell SS (2002) Modeling seagrass landscape pattern and associated ecological attributes. Ecol Appl 12:218-237

Fonseca MS, Whitfield PE, Kenworthy WJ, Colby DR, Julius BE (2004) Use of two spatially explicit models to determine the effect of injury geometry on natural resource recovery. Aquat Cons Mar Freshw Ecosys 14:281-298

Grigg RW (1998) Holocene coral reef accretion in Hawaii: a function of wave exposure and sea level history. Coral Reefs 17:263-272

Grime JP (1977) Evidence for the existence of three primary strategies in plants and its relevance to ecological and evolutionary theory. Am Nat 111:1169-1194

Guichard F (2005) Interaction strength and extinction risk in a metacommunity. Proc R Soc Lond B 272:1571-1576

Hemminga M, Duarte C (2000) Seagrass ecology. Cambridge University Press, Cambridge

Hewitt JE, Cummings VJ, Ellis JI, Funnell G, Norkko A, Talley TS, Thrush SF (2003) The role of waves in the colonisation of terrestrial sediments deposited in the marine environment. J Exp Mar Biol Ecol 290:19-47

Hughes AR, Bando KJ, Rodriguez LF, Williams SL (2004) Relative effects of grazers and nutrients on seagrasses: a meta-analysis approach. Mar Ecol Prog Ser 282:87-99

Keddy PA (1989) Competition. Chapman \& Hall, London

Keddy PA (1992) Assembly and response rules-2 goals for predictive community ecology. J Veg Sci 3:157-164

Keselman HJ (1976) A power comparison of the Tukey multiple comparison statistic. Edu Psychol Meas 36:97-104

Knowlton N (2004) Multiple 'stable' states and the conservation of marine ecosystems. Prog Oceanogr 60:387-396

Levin SA, Paine RT (1974) Disturbance, patch formation, and community structure. Proc Natl Acad Sci USA 71: $2744-2747$

Lewis JB (2002) Evidence from aerial photography of structural loss of coral reefs at Barbados, West Indies. Coral Reefs 21:49-56

Lewis JB, Oxenford HA (1996) A field guide to the coral reefs of Barbados. McGill University, Montreal

Editorial responsibility: Kenneth Heck (Contributing Editor), Dauphin Island, Alabama, USA
Littler MM, Littler DS, Brooks BL (2004) Extraordinary mound-building forms of Avrainvillea (Bryopsidales, Chlorophyta): their experimental taxonomy, comparative functional morphology and ecological strategies. Atoll Res Bull 515:1-26

Masselink G, Short A (1993) The influence of tidal range on beach morphodynamics: A conceptual model. J Coast Res 9:785-800

McClelland JW, Valiela I (1998) Changes in food web structure under the influence of increased anthropogenic nitrogen inputs to estuaries. Mar Ecol Prog Ser 168: $259-271$

Nielsen K (2003) Nutrient loading and consumers: agents of change in open-coast macrophyte assemblages. Proc Natl Acad Sci USA 100:7660-7665

Paine R, Levin S (1981) Intertidal landscapes: disturbance and the dynamics of pattern. Ecol Monogr 51:145-178

Patriquin DG (1975) 'Migration' of blowouts in seagrass beds at Barbados and Carriacou, West Indies, and its ecological and geological implications. Aquat Bot 1:163-189

Peterson BJ, Rose CD, Rutten LM, Fourqurean JW (2002) Disturbance and recovery following catastrophic grazing: studies of successional chronosequence in a seagrass bed. Oikos 97:361-370

Pickett S, White P (1985) The ecology of natural disturbance and patch dynamics. Academic Press, Orlando, FL

Robbins BD, Bell SS (2000) Dynamics of a subtidal seagrass landscape: Seasonal and annual change in relation to water depth. Ecology 81:1193-1205

Rose CD, Sharp WC, Kenworthy WJ, Hunt JH and 6 others (1999) Overgrazing of a large seagrass bed by the sea urchin Lytechinus variegatus in outer Florida Bay. Mar Ecol Prog Ser 190:211-222

Scheffer M, Carpenter S (2003) Catostrophic regime shifts in ecosystems: linking theory to observation. Trends Ecol Evol 18:648-656

Short FT, Wyllie-Echeverria S (1996) Natural and humaninduced disturbance of seagrasses. Environ Conserv 23: $17-27$

Siddon CE, Witman JD (2003) Influence of chronic, low-level hydrodynamic forces on subtidal community structure. Mar Ecol Prog Ser 261:99-110

Sousa WP (1984) The role of disturbance in natural communities. Annu Rev Ecol Syst 15:353-391

Sousa WP (2000) Natural disturbance and the dynamics of marine benthic communities. In: Bertress MD, Gaines SD, Hay ME (eds) Marine community ecology. Sinauer Associates, Sunderland, MA, p 85-130

Steneck RS, Dethier MN (1994) A functional group approach to the structure of algal-dominated communities. Oikos 69:476-498

Sutherland JP (1974) Multiple stable points in natural communities. Am Nat 108:859-873

Sutherland JP (1990) Perturbations, resistance, and alternative views of the existence of multiple stable points in nature. Am Nat 136:270-275

Whitfield PE, Kenworthy WJ, Hammerstrom KA, Fonseca MS (2002) Storm induced susceptibility of vessel groundings. J Coast Res 37:86-99

Williams SL (1987) Competition between the seagrasses Thalassia testudinum and Syringodium filiforme in a Caribbean lagoon. Mar Ecol Prog Ser 35:91-98

Williams SL (1990) Experimental studies of Caribbean seagrass bed development. Ecol Monogr 60:449-469

Zar JH (1999) Biostatistical analysis, 4th edn. Prentice-Hall, London

Submitted: October 14, 2005; Accepted: September 8, 2006

Proofs received from author(s): April 4, 2007 